\title{
Maternal and obstetric complications in fetal surgery for prenatal myelomeningocele repair: a systematic review
}

\author{
Maria Licci, MD, ${ }^{1,2}$ Raphael Guzman, MD, ${ }^{1-3}$ and Jehuda Soleman, MD ${ }^{1-3}$ \\ ${ }^{1}$ Department of Neurosurgery, University Hospital of Basel; 'Division of Pediatric Neurosurgery, Children's University Hospital of \\ Basel; and ${ }^{3}$ Faculty of Medicine, University of Basel, Switzerland
}

\begin{abstract}
OBJECTIVE Comparing prenatal and postnatal surgical repair techniques for myelomeningocele (MMC), in utero fetal surgery has increasingly gained acceptance and is considered by many specialized centers the first choice of treatment. Despite its benefits, as demonstrated in the Management of Myelomeningocele Study (MOMS), including reduced need for CSF shunting in neonates and improved motor outcomes at 30 months, there is still an ongoing debate on fetal and maternal risks associated with the procedure. Prenatal open hysterotomy, fetoscopic MMC repair techniques, and subsequent delivery by cesarean section are associated with maternal complications. The aim of this systematic review is to assess the available literature on maternal and obstetric complication rates and perinatal maternal outcomes related to fetal MMC repair.
\end{abstract}

METHODS The authors identified references for inclusion in this review by searching PubMed and MEDLINE, with restrictions to English language, case series, case reports, clinical trials, controlled clinical trials, meta-analyses, randomized controlled trials, reviews, and systematic reviews. The rate of maternal and obstetric complications was analyzed based on studies focusing on this issue and presenting clear results on the matter.

RESULTS Of 1264 articles screened, 36 were included in this systemic review, whereof 11 were eligible for data analysis and comparison. The average overall rate of maternal and obstetric complications corresponds to $78.6 \%$. The majority of the described events are obstetric complications, varying from chorioamniotic membrane separation in $65.6 \%$ of cases, oligohydramnios in $13.0 \%$ of cases, placental abruption in $5.0 \%$ of cases, spontaneous or preterm premature membrane rupture in $42.0 \%$ of cases, and early preterm delivery in $11.3 \%$ of cases due to uterine dehiscence, occurring in $0.9 \%$ of cases. The most common medical complications are development of pulmonary edema occurring in $2.8 \%$, gestational diabetes in 3.7\%, gestational hypertension/preeclampsia in 3.7\%, and need for blood transfusions in $3.2 \%$ of cases. Limitations of the review arise from the lack of data in the current literature, with maternal and obstetric complications being underreported.

CONCLUSIONS Although the efforts of further advancement of intrauterine prenatal MMC repair aim to increase neonatal outcomes, maternal health hazard will continue to be an issue of crucial importance and further studies are required.

https://thejns.org/doi/abs/10.3171/2019.7.FOCUS19470

KEYWORDS myelomeningocele; fetal surgery; prenatal repair; maternal complications; maternal outcome

$\mathrm{M}$ YELOMENINGOCELE (MMC) is the most common congenital anomaly of the central nervous system compatible with life. It consists in failure of closure of the neural tube within the first 6 weeks of gestation. $1,18,26,27,36$ Although individuals affected with MMC may reach adulthood in a percentage rate of up to $75 \%$, liveborn infants have a death rate of approximately $10 \%$ in the first year of life, increasing to $30 \%$ within the first 5 years of life., ${ }^{9,26,29}$ Long-term survivors often suffer from major lifelong disabilities, including hydrocephalus, paraplegia, hindbrain herniation as part of a Chiari II malformation, incontinence, sexual dysfunction, mental impairment, and skeletal deformities. ${ }^{1,9,26}$ Postnatal standard of care of infants born with MMC entails early surgical closure within the first 24-48 hours of life, but despite the surgical repair the neurological damage is irreversible. The majority of

ABBREVIATIONS CMS = chorioamniotic membrane separation; $M M C=$ myelomeningocele; $M O M S$ = Management of Myelomeningocele Study; $P P R O M=$ premature preterm rupture of membranes; PTD = preterm delivery; $S R O M=$ spontaneous rupture of membranes.

SUBMITTED June 1, 2019. ACCEPTED July 22, 2019.

INCLUDE WHEN CITING DOI: 10.3171/2019.7.FOCUS19470. 
infants born with MMC develop hydrocephalus and are in need of CSF diversion in up to $80 \%$ of the cases. ${ }^{1,9,29}$ Furthermore, the severity of sensorimotor impairment is associated with the level of the spinal cord lesion and can be even higher than the location of the vertebral defect. ${ }^{1,26,27,29}$ The use of maternal-fetal prenatal surgery for nonlethal conditions, such as MMC, is highly controversial. ${ }^{24}$ Nonetheless, MMC has been the first, nonlethal condition explored by fetal surgery, due to the increasing rate of early gestational diagnosis through screening programs and advancement of prenatal imaging methods on one hand, and data suggesting a progressive deterioration of both central and peripheral neurological damage during fetal gestation, due to the "2-hit" hypothesis (initial embryonic neurulation failure and secondary damage due to exposure of the spinal cord to the intrauterine environment), on the other hand.,17,18,25 The objective of the prenatal therapeutic approach is to minimize the extent of the neurological damage and hydrocephalus and therefore improve neonatal outcomes. Data resulting initially from nonrandomized studies and subsequently from the Management of Myelomeningocele Study (MOMS) showed significantly lower rates of hindbrain herniation and CSF diversion procedures and improvement of motor function at 30 months of age in the fetal surgery group compared to the postnatal surgery group. ${ }^{1,2,14,16,26,27}$ Fetal MMC repair is, however, associated with pre- and perinatal maternal complications. These complications are mostly related to early gestational hysterotomy, in addition to chorioamniotic membrane separation (CMS), oligohydramnios, and uterine dehiscence. . $, 5,26,27,31$ Maternal complications increase the perinatal risk, may also endanger subsequent pregnancies, and lead to preterm delivery (PTD). ${ }^{13,14,19,20,22 \text {, }}$ ${ }^{33,34}$ The objective of this systematic review is to describe maternal complications associated with fetal MMC repair and their rate of occurrence.

\section{Methods}

References for this systematic review were identified by searching PubMed and MEDLINE, inserting the terms "myelomeningocele AND fetal," "myelomeningocele AND repair," "myelomeningocele AND utero," "myelomeningocele AND maternal," "myelomenigocele AND mother," "myelomeningocele AND complications," "myelomeningocele AND prenatal," "fetal surgery AND complications," "myelomeningocele AND fetoscopy," "fetal surgery AND complications," "fetal surgery AND myelomeningocele," "MOMS Trial AND maternal," and "MOMS trial AND complications," with restrictions to English language, case series, case reports, clinical trials, controlled clinical trials, meta-analyses, randomized controlled trials, reviews, and systematic reviews. Abstracts were reviewed, excluding duplicates and studies focused primarily on fetal outcome and/or those with insufficient data on maternal and obstetric complications and outcome. The rate of maternal and obstetric complications was analyzed based on studies focusing on this issue and presenting clear results on the matter. There is a partial overlap of the cases described in the MOMS trial publication from $2011^{1}$ and the analysis of the data emerging from the complete MOMS cohort, published in 2016. ${ }^{16}$ Therefore, these patients $(n=78)$ were subtracted from the cohort analysis.

\section{Results}

A total of 1261 records were identified through the database searches, and 3 additional records were identified through references within selected records. A total of 1171 records were excluded based on title or abstract review. Of the 42 remaining records, 6 were excluded with reason, resulting in 36 articles being included in the review. ${ }^{1-36}$ Of these, 11 included data on maternal and obstetric complications and were therefore included in the final analysis (Fig. 1).,14-6,10,16,21,26,30,35,36 These studies consisted of 1 randomized controlled trial, ${ }^{1} 7$ prospective cohort studies, $, 5,6$, 16,26,30,35,36 and 3 retrospective analyses ${ }^{4,10,21}$ (Table 1). Six publications describe open-access techniques, ${ }^{1,5,16,26,35,36} 1$ publication describes a modified open-access technique with mini-hysterotomy, ${ }^{6}$ and 4 trials describe fetoscopic procedures. ${ }^{4,10,21,30}$ Furthermore, 2 studies focus on the reproductive consequences after a pregnancy complicated by maternal-fetal surgery for MMC repair. ${ }^{13,33}$ Overall, the analyzed studies reported data from 518 women who underwent fetal MMC repair, out of which there were 7 studies describing 435 open-access procedures through laparotomy and hysterotomy, including 39 cases treated with a modified, less invasive open technique ${ }^{5}$ and 83 cases of minimally invasive, fetoscopic MMC repair. ${ }^{4,10,21,30}$

\section{Maternal and Obstetric Complications in Fetal MMC Repair}

Maternal morbidity and obstetric complications that can be related to prenatal surgery include those of obstetric focus, linked to the need of uterine access with potential subsequent leakage of amniotic fluid, such as oligohydramnios, CMS, placental abruption, and spontaneous membrane rupture. These factors are associated with a substantial risk of PTD.

Based on the analyzed cohort, the mean gestational age at birth was $34.7 \pm 4.1$ weeks, with an $11.3 \%$ rate of PTD before 30 weeks of gestation. Chorioamniotic membrane separation occurred in $65.6 \%$ of the pregnancies and oligohydramnios was present in $13.0 \%$. Spontaneous rupture of membranes (SROM) and premature preterm rupture of membranes (PPROM) at any gestational age occurred in $42.0 \%$ of the pregnancies. Uterus rupture occurred in $1.56 \%$ of the cases, all in the open cohort, and placenta abruption was seen in $5.0 \%$ of the pregnancies. No maternal deaths occurred, but $3.2 \%$ of the women, all in the open cohort, needed blood transfusion at delivery. Pulmonary edema was described in $2.8 \%$ of the cases, while data on gestational diabetes were present in $3.7 \%$ of the cases. ${ }^{1,16,35,36} \mathrm{An}$ area of thinning or dehiscence of the uterine surgery scar at time of cesarean delivery was present in 21.5.\% of open fetal MMC repair, whereas this complication did not occur in the fetoscopy group. Table 2 summarizes the rate of maternal and obstetric complications and the difference between open and endoscopic fetal MMC repair based on the systematic review of the literature.

Overall, the main cause for perinatal morbidity in the 


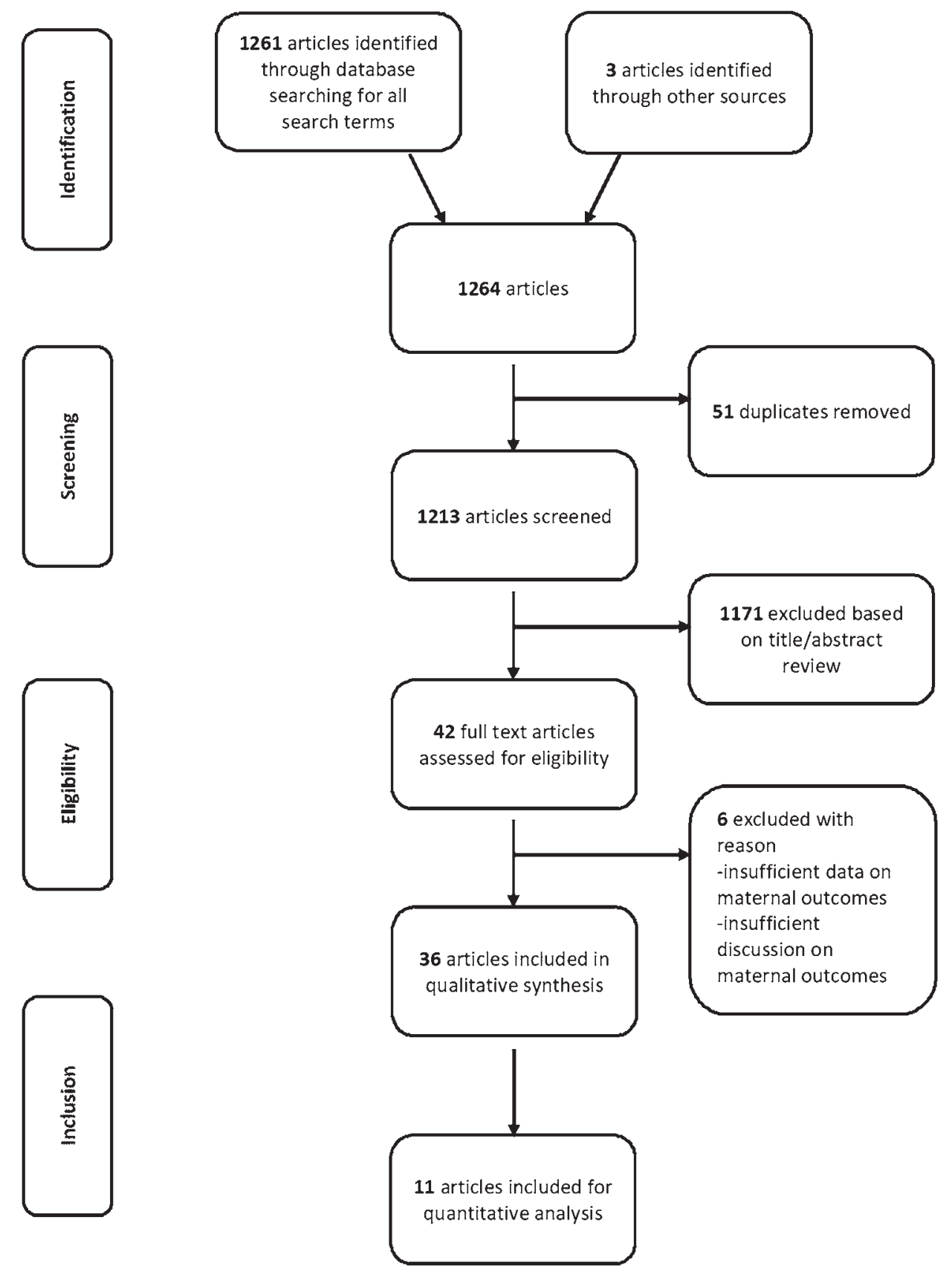

FIG. 1. Article selection flowchart.

open-access technique seems to be the large incision needed for the hysterotomy. This potentially leads to the development of a thinning or dehiscence of the uterine wall, $3,17,18,28,31$ carrying the risk of relevant peripartum bleeding and potentially compromising uterine integrity for subsequent pregnancies. ${ }^{13,35}$ Considering maternal outcome, including pregnancy-related complications, the described complication rate amounts to up to $80 \%,{ }^{16,35}$ in accordance with this systemic literature review, showing an overall complication rate of $78.6 \%$. No maternal deaths have been reported with either open or fetoscopic access for prenatal MMC repair.

\section{Rationale for Fetal MMC Repair}

The benefits of fetal MMC repair have been described extensively, 1,2,9,16-20,26,27,34 however, it is clear from our systematic literature search that data on the maternal and obstetric risk are sparse and the maternal and obstetric complication rates are still underreported.

The procedure of fetal MMC repair is invasive and carries risk for both the mother and the fetus. ${ }^{1,5,13,16-20,22 \text {, }}$ 26,27,31,33-35 One must stress that fetal surgery and its potential maternal risks endanger the mother, which is not the case if treatment is performed postnatally. Bennett et al. modified the technique of hysterotomy opening and 
Licci et al.

TABLE 1. Overview of studies selected for comparative analysis

\begin{tabular}{|c|c|c|c|c|}
\hline Authors \& Year & Journal & Study Type & $\begin{array}{l}\text { Prenatal } \\
\text { Cohort (n) }\end{array}$ & Surgical Uterine Access \\
\hline Adzick et al., 2011 & N Engl J Med & RCT & 78 & Open laparotomy, stapled hysterotomy \\
\hline Belfort et al., 2017 & Obstet Gynecol & Retrospective, single-center & 22 & 2-port fetoscopy, amniotic $\mathrm{CO}_{2}$ insufflation \\
\hline Bennett et al., 2014 & $\begin{array}{l}\text { J Neurosurg } \\
\text { Pediatr }\end{array}$ & $\begin{array}{l}\text { Prospective nonrandomized, } \\
\text { single-center }\end{array}$ & 41 & $\begin{array}{l}\text { Open laparotomy, stapled hysterotomy, stabili- } \\
\text { zation of amniotic membrane to uterine wall }\end{array}$ \\
\hline Botelho et al., 2017 & Fetal Diagn Ther & $\begin{array}{l}\text { Prospective nonrandomized, } \\
\text { single-center }\end{array}$ & 39 & $\begin{array}{l}\text { Open mini-hysterotomy, suturing of amniotic } \\
\text { membranes to uterine wall }\end{array}$ \\
\hline Johnson et al., 2016 & $\begin{array}{l}\text { Am J Obstet } \\
\text { Gynecol }\end{array}$ & $\begin{array}{l}\text { Prospective randomized, multi- } \\
\text { center (MOMS complete cohort) }\end{array}$ & 91 & Open laparotomy, stapled hysterotomy \\
\hline $\begin{array}{l}\text { Kohl, } 2014 \text { (Part I); Degen- } \\
\text { hardt et al., } 2014 \text { (Part II) }\end{array}$ & $\begin{array}{l}\text { Ultrasound Obstet } \\
\text { Gynecol }\end{array}$ & Retrospective, single-center & 51 & 3-port fetoscopy, amniotic $\mathrm{CO}_{2}$ insufflation \\
\hline Moldenhauer \& Adzick, 2017 & $\begin{array}{l}\text { Semin Fetal Neo- } \\
\text { natal Med }\end{array}$ & $\begin{array}{l}\text { Prospective nonrandomized, } \\
\text { single-center }\end{array}$ & 100 & Open laparotomy, stapled hysterotomy \\
\hline Pedreira et al., 2016 & $\begin{array}{l}\text { Am J Obstet } \\
\text { Gynecol }\end{array}$ & $\begin{array}{l}\text { Prospective nonrandomized, } \\
\text { single-center }\end{array}$ & 10 & 3-port fetoscopy, amniotic $\mathrm{CO}_{2}$ insufflation \\
\hline Winder et al., 2018 & Fetal Diagn Ther & $\begin{array}{l}\text { Prospective nonrandomized, } \\
\text { single-center }\end{array}$ & 40 & Open laparotomy, stapled hysterotomy \\
\hline Zamłyński et al., 2014 & $\begin{array}{l}\text { J Matern Fetal } \\
\quad \text { Neonatal Med }\end{array}$ & $\begin{array}{l}\text { Prospective nonrandomized, } \\
\text { single-center }\end{array}$ & 46 & Open laparotomy, hysterotomy \\
\hline
\end{tabular}

$\mathrm{RCT}=$ randomized controlled trial.

closure. 5 They apply sutures to stabilize the amniotic membrane and open it under direct visualization while securing it to the uterine wall. They postulate that this less-traumatic maneuver helps to avoid CMS, reducing the rate of PTD. They reported a significantly lower rate of CMS, a trend toward reduction of premature rupture of membranes, higher gestational age at delivery, and higher rates of intact hysterotomy sites at delivery, compared to the MOMS trial. Apart from one case of pneumonia requiring treatment at an intensive care unit, there were no other relevant surgery-related complications. Botelho et al. describe a modification of the classic open-access surgery, using a $2.5-$ to $3.5-\mathrm{cm}$ mini-hysterotomy, in a small cohort of 45 patients. ${ }^{6}$ They showed a higher rate of intact

TABLE 2. Quantitative comparative maternal and obstetric outcome analysis

\begin{tabular}{|c|c|c|c|c|c|c|c|}
\hline \multirow[b]{2}{*}{ Complication } & \multicolumn{2}{|c|}{ Complete Cohort } & \multicolumn{2}{|c|}{ Open-Access Cohort } & \multicolumn{2}{|c|}{ Fetoscopic Cohort } & \multirow[b]{2}{*}{ OR $(95 \% \mathrm{Cl})$} \\
\hline & Present & Absent & Present & Absent & Present & Absent & \\
\hline Total & $103(78.6)$ & 131 & $103(78.6)$ & 131 & NA & NA & NA \\
\hline CMS & $86(65.6)$ & 131 & $73(20.4)$ & 284 & $13(15.6)$ & 70 & $1.38(0.73-2.64)$ \\
\hline Oligohydramnios & $57(13.0)$ & 440 & $43(12.0)$ & 314 & $14(16.9)$ & 69 & $1.40(0.77-2.86)$ \\
\hline Placental abruption & $17(5.0)$ & 340 & $14(5.4)$ & 212 & $3(3.6)$ & 80 & $1.76(0.49-6.29)$ \\
\hline Chorioamnionitis & $9(3.0)$ & 301 & $6(2.8)$ & 212 & $3(3.6)$ & 80 & $1.33(0.32-5.42)$ \\
\hline SROM & $185(42.0)$ & 440 & $127(35.6)$ & 230 & $58(69.8)$ & 25 & $4.20(2.51-7.04)$ \\
\hline Non-intact hysterotomy site at delivery* & $86(21.5)$ & 400 & $86(21.5)$ & 231 & $0(0)$ & 73 & NA \\
\hline Pulmonary edema & $11(2.8)$ & 399 & $8(2.5)$ & 308 & $3(3.6)$ & 80 & $1.44(0.37-5.57)$ \\
\hline Blood transfusion at delivery & $14(3.2)$ & 440 & $14(3.9)$ & 343 & $0(0)$ & 83 & NA \\
\hline Gestational diabetes & $16(3.7)$ & 177 & $16(3.7)$ & 177 & NA & NA & NA \\
\hline Gestational hypertension/preeclampsia & $8(3.7)$ & 216 & $8(3.7)$ & 216 & NA & NA & NA \\
\hline Early PTD <30 wks of gestation & $34(11.3)$ & 299 & $27(11.9)$ & 199 & $7(9.6)$ & 66 & $1.28(0.53-3.07)$ \\
\hline Mean gestational age at birth in wks & \multicolumn{2}{|c|}{$34.8 \pm 4.1$} & \multicolumn{2}{|c|}{$34.5 \pm 4.2$} & \multicolumn{2}{|c|}{$36 \pm 2.7$} & NA \\
\hline
\end{tabular}

$\mathrm{NA}=$ not applicable.

Analysis is based on available data from within the included studies. Data are presented for "present" as n (\%), for "absent" as n, unless otherwise indicated. Mean values are presented with standard deviations. Odds ratios (OR) represent the difference between open and fetoscopic cohorts.

* Thinning or partial dehiscence. 
hysterotomy site at delivery and an increase in the rate of late PTD compared to open-access surgery, despite similar average gestational age at delivery. The frequency of CMS and PPROM was slightly lower than reported in the MOMS trial. Placental abruption occurred in $2.6 \%$ of the cases, without occurrence of other major adverse events, namely pulmonary edema or the need for maternal transfusions. As in the studies by Bennett et al. and Botelho et al., research efforts should be aimed at developing further strategies in fetal MMC repair and reducing maternal and obstetric complications, as well as improving maternal

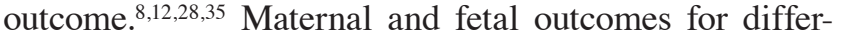
ent techniques must be compared directly and analyzed. Generally, all studies analyzing fetal MMC repair should report the possible maternal complications and their occurrence rates, while in addition, series looking specifically into the maternal risk of fetal MMC repair should be sought. Apart from the current improvements of technique, since the actual cumulative complication rate for the mother in fetal MMC repair is up to $80 \%$ (similar to shunt rates in open surgery), it is crucial that the parents are rigorously informed, not only about the potential benefits for the child, but also about the high risks that fetal MMC repair carries for the mother and for PTD.

\section{Patient Selection for Fetal MMC Repair: Maternal Aspects}

According to the inclusion and exclusion criteria of the MOMS trial, women with multiple gestation, BMI $>35$ $\mathrm{kg} / \mathrm{m}^{2}$, increased risk for preterm birth $<37$ weeks of gestation, abnormal placentation, uterine anomalies including previous hysterotomy in the active uterine segment, and systemic maternal conditions that would increase the maternal risk, as well as women with the presence of psychosocial limitations, do not qualify for fetal MMC repair. Johnson et al., with regard to the complete cohort of 91 women assigned to the fetal group of the MOMS trial, evaluated risk factors for 5 maternal and obstetric complications, namely CMS, SROM, PPROM, PTD, and non-intact hysterotomy. ${ }^{16}$ Patients undergoing fetal MMC repair showed an incidence of $81 \%$ for at least one of these complications in addition to a significantly increased risk of $11 \%$ for PTD before 30 weeks of gestation. Furthermore, the authors reported a significant increase in placental abruption, pulmonary edema, and the need for maternal transfusion at delivery in the fetal-MMC-repair group. Two studies subsequently analyzed data for maternal complications after open fetal MMC repair with similar criteria, but including women with extended BMI limits..$^{15,35}$ Hilton et al. evaluated outcomes of in utero MMC repair in 11 patients with extended BMI criteria of $35-40 \mathrm{~kg} / \mathrm{m}^{2}$ and found that the average gestational age at delivery was 2 weeks less than in the original trial (MOMS), but there were no adverse systemic maternal outcomes associated with maternal obesity. ${ }^{15}$ Actual detailed data on maternal and obstetric complications in fetoscopic MMC repair, whose early approaches date back to the late 1990s, prior to the introduction of open fetal surgery ${ }^{7,11,18}$ are available in 4 studies. ${ }^{4,10,21,30}$ However, a comparative analysis of the impact on maternal complications is only possible for 2 of these studies, ${ }^{10,21}$ since the other 2 studies $^{4,30}$ consist of very small cohorts. Kohl ${ }^{21}$ and Degenhardt et al. ${ }^{10}$ de- scribed the maternal management and outcome of a percutaneous minimal access fetoscopic surgery procedure for MMC, using 3 trocars and amniotic carbon dioxide insufflation of the abdominal cavity. Retrospective data from 51 cases showed a mean gestational age at birth of 32.9 weeks, with $11.8 \%(\mathrm{n}=6)$ PTDs prior to 30 weeks of gestation. There were lower rates of maternal and relevant obstetric complications, and no placenta abruption or uterus rupture were apparent. Nevertheless, there was a higher rate of amniotic fluid leakage (84.3\%) from iatrogenic membrane injury with 3 cases of chorioamnionitis, leading to fetal death in 1 case..$^{10,21}$

Based on our systematic literature review, studies analyzing possible maternal risk factors for higher maternal and obstetric complication rates in any kind of fetal MMC repair are sparse. Therefore, there are no robust data on which mothers are ideal candidates for fetal MMC repair and what technique should be preferred and under which circumstances. Further, examining the MOMS inclusion criteria more closely shows that only $16.8 \%$ of the 1087 women who were considered for fetal MMC repair met the inclusion criteria and were recruited in the original trial. ${ }^{1}$ Similarly, in a study published by Moldenhauer and Adzick, applying the selection criteria from the MOMS protocol, the proportion of women considered eligible for fetal MMC repair and accepting fetal surgery out of the screened cohort was $17.7 \% .{ }^{26}$ It emerges from the above that the incomplete cohorts resulting from patient selection, going along with clinical and methodological heterogeneity, impede a systematic analysis of maternal and obstetric complications. Laskay et al. conducted a singleinstitution cohort analysis of mothers contemporaneous with MOMS to determine the generalizability of MOMS results, concluding that mothers in their cohort differed from those enrolled in MOMS via several sociodemographic factors and stating that revision of the criteria changed the result in their cohort. ${ }^{23}$

In summary, to date, the indication or contraindication for fetal MMC repair, from the mother's point of view, remains unclear and without a solid evidence base. Until further studies are published that analyze potential risk factors for maternal and obstetric complications in fetal MMC repair, this issue must be presented in an open and honest way, stating the still relatively high risk of maternal complications, when discussing options with parents.

\section{Subsequent Pregnancies}

To date, 2 studies have analyzed the outcome of subsequent pregnancies in women who underwent fetal MMC repair. ${ }^{13,35}$ Goodnight et al. ${ }^{13}$ analyzed maternal complications in 77 reported subsequent pregnancies out of an international multicenter prospective registry, including 693 patients. Wilson et al..$^{34}$ also analyzed reproductive outcomes after pregnancies that were complicated by maternal-fetal surgery, including $52 \mathrm{MMC}$ malformations in their retrospective cohort of 83 cases. The results were similar to results reported for subsequent pregnancies after classic cesarean deliveries, although there was a significantly higher risk of uterine rupture or dehiscence in subsequent pregnancies after fetal MMC repair. 


\section{Conclusions}

Based on our systematic review, the risk of maternal and obstetric complications in fetal MMC repair surgery should not be neglected, since these complications occur relatively often. The most frequent complications seem to be CMS and SROM, occurring in $65.6 \%$ and $42.0 \%$ of the cases, respectively, leading to a higher risk of PTD. Studies analyzing specifically maternal and obstetric complications are sparse, while in other studies on fetal MMC repair these complications are underreported or not reported at all. Therefore, it is difficult to draw firm conclusions. However, when obtaining parental consent for fetal MMC repair surgery, treating centers must not only discuss with the parents the benefits of surgery for the fetus, but also discuss the possible and relatively high risk for maternal and obstetric complications-especially since the mother is exposed to risks during and after fetal MMC repair that are not apparent in postnatal MMC repair. Further studies focusing on improving and comparing fetal MMC repair techniques, analyzing risk factors for maternal complications, looking at possible risks for subsequent pregnancies, and reporting on maternal complications are needed in order for treating physicians to obtain truly informed consent from and provide optimal treatment for affected families.

\section{References}

1. Adzick NS, Thom EA, Spong CY, Brock JW III, Burrows PK, Johnson MP, et al: A randomized trial of prenatal versus postnatal repair of myelomeningocele. N Engl J Med 364:993-1004, 2011

2. Araujo Júnior E, Eggink AJ, van den Dobbelsteen J, Martins WP, Oepkes D: Procedure-related complications of open vs endoscopic fetal surgery for treatment of spina bifida in an era of intrauterine myelomeningocele repair: systematic review and meta-analysis. Ultrasound Obstet Gynecol 48:151-160, 2016

3. Barini R, Barreto MWG, Cursino K, Zambelli H, Prando A, Sbragia L: Abruptio placentae during fetal myelomeningocele repair. Fetal Diagn Ther 21:115-117, 2006

4. Belfort MA, Whitehead WE, Shamshirsaz AA, Bateni ZH, Olutoye OO, Olutoye OA, et al: Fetoscopic open neural tube defect repair: development and refinement of a two-port, carbon dioxide insufflation technique. Obstet Gynecol 129:734-743, 2017

5. Bennett KA, Carroll MA, Shannon CN, Braun SA, Dabrowiak ME, Crum AK, et al: Reducing perinatal complications and PTD for patients undergoing in utero closure of fetal myelomeningocele: further modifications to the multidisciplinary surgical technique. J Neurosurg Pediatr 14:108-114, 2014

6. Botelho RD, Imada V, Rodrigues da Costa KJ, Watanabe LC, Rossi Júnior R, De Salles AAF, et al: Fetal myelomeningocele repair through a mini-hysterotomy. Fetal Diagn Ther 42:28-34, 2017

7. Bruner JP, Tulipan NB, Richards WO, Walsh WF, Boehm FH, Vrabcak EK: In utero repair of myelomeningocele: a comparison of endoscopy and hysterotomy. Fetal Diagn Ther 15:83-88, 2000

8. Corral E, Sepulveda W, Ravera F, Muller JM, Tapia M, Reascos M, et al: Use of plastic wound retractor at hysterotomy site in prenatal repair of myelomeningocele: a new technique. J Matern Fetal Neonatal Med [epub ahead of print], 2019

9. Danzer E, Adzick NS: Fetal surgery for myelomeningocele: patient selection, perioperative management and outcomes. Fetal Diagn Ther 30:163-173, 2011

10. Degenhardt J, Schürg R, Winarno A, Oehmke F, Khaleeva A, Kawecki A, et al: Percutaneous minimal-access fetoscopic surgery for spina bifida aperta. Part II: maternal management and outcome. Ultrasound Obstet Gynecol 44:525-531, 2014

11. Farmer DL, von Koch CS, Peacock WJ, Danielpour M, Gupta $\mathrm{N}$, Lee $\mathrm{H}$, et al: In utero repair of myelomeningocele: experimental pathophysiology, initial clinical experience, and outcomes. Arch Surg 138:872-878, 2003

12. Giné C, Arévalo S, Maíz N, Rodó C, Manrique S, Poca A, et al: Fetoscopic two-layer closure of open neural tube defects. Ultrasound Obstet Gynecol 52:452-457, 2018

13. Goodnight WH, Bahtiyar O, Bennett KA, Emery SP, Lillegard JB, Fisher A, et al: Subsequent pregnancy outcomes after open maternal-fetal surgery for myelomeningocele. Am J Obstet Gynecol 220:494.e1-494.e7, 2019

14. Grivell RM, Andersen C, Dodd JM: Prenatal versus postnatal repair procedures for spina bifida for improving infant and maternal outcomes. Cochrane Database Syst Rev (10):CD008825, 2014

15. Hilton SA, Hodges MM, Dewberry LC, Handler M, Galan HL, Zaretsky MV, et al: MOMS Plus: single-institution review of outcomes for extended BMI criteria for open fetal repair of myelomeningocele. Fetal Diagn Ther [epub ahead of print], 2019

16. Johnson MP, Bennett KA, Rand L, Burrows PK, Thom EA, Howell LJ, et al: The Management of Myelomeningocele Study: obstetrical outcomes and risk factors for obstetrical complications following prenatal surgery. Am J Obstet Gynecol 215:778.e1-778.e9, 2016

17. Joyeux L, Danzer E, Flake AW, Deprest J: Fetal surgery for spina bifida aperta. Arch Dis Child Fetal Neonatal Ed 103:F589-F595, 2018

18. Joyeux L, Engels AC, Russo FM, Jimenez J, Van Mieghem $\mathrm{T}$, De Coppi P, et al: Fetoscopic versus open repair for spina bifida aperta: a systematic review of outcomes. Fetal Diagn Ther 39:161-171, 2016

19. Kabagambe SK, Chen YJ, Vanover MA, Saadai P, Farmer DL: New directions in fetal surgery for myelomeningocele. Childs Nerv Syst 33:1185-1190, 2017

20. Kabagambe SK, Jensen GW, Chen YJ, Vanover MA, Farmer DL: fetal surgery for myelomeningocele: a systematic review and meta-analysis of outcomes in fetoscopic versus open repair. Fetal Diagn Ther 43:161-174, 2018

21. Kohl T: Percutaneous minimally invasive fetoscopic surgery for spina bifida aperta. Part I: surgical technique and perioperative outcome. Ultrasound Obstet Gynecol 44:515-524, 2014

22. Kohn JR, Rao V, Sellner AA, Sharhan D, Espinoza J, Shamshirsaz AA, et al: Management of labor and delivery after fetoscopic repair of an open neural tube defect. Obstet Gynecol 131:1062-1068, 2018

23. Laskay NMB, Arynchyna AA, McClugage SG III, Hopson B, Shannon C, Ditty B, et al: A comparison of the MOMS trial results to a contemporaneous, single-institution, postnatal closure cohort. Childs Nerv Syst 33:639-646, 2017

24. Lyerly AD, Cefalo RC, Socol M, Fogarty L, Sugarman J: Attitudes of maternal-fetal specialists concerning maternal-fetal surgery. Am J Obstet Gynecol 185:1052-1058, 2001

25. Meuli M, Moehrlen U: Fetal surgery for myelomeningocele is effective: a critical look at the whys. Pediatr Surg Int 30:689-697, 2014

26. Moldenhauer JS, Adzick NS: Fetal surgery for myelomeningocele: After the Management of Myelomeningocele Study (MOMS). Semin Fetal Neonatal Med 22:360-366, 2017

27. Moldenhauer JS, Soni S, Rintoul NE, Spinner SS, Khalek N, Martinez-Poyer J, et al: Fetal myelomeningocele repair: the 
post-MOMS experience at the Children's Hospital of Philadelphia. Fetal Diagn Ther 37:235-240, 2015

28. Moron AF, Barbosa MM, Milani HJF, Sarmento SG, Santana EFM, Suriano IC, et al: Re: Perinatal outcomes after open fetal surgery for myelomeningocele repair: a retrospective cohort study. BJOG 126:131-132, 2019

29. Pedreira DAL, Zanon N, Nishikuni K, Moreira de Sá RA, Acacio GL, Chmait RH, et al: Endoscopic surgery for the antenatal treatment of myelomeningocele: the CECAM trial. Am J Obstet Gynecol 214:111.e1-111.e11, 2016

30. Peranteau WH, Adzick NS: Prenatal surgery for myelomeningocele. Curr Opin Obstet Gynecol 28:111-118, 2016

31. Soni S, Moldenhauer JS, Spinner SS, Rendon N, Khalek N, Martinez-Poyer J, et al: Chorioamniotic membrane separation and preterm premature rupture of membranes complicating in utero myelomeningocele repair. Am J Obstet Gynecol 214:647.e1-647.e7, 2016

32. Verbeek RJ, Heep A, Maurits NM, Cremer R, Hoving EW, Brouwer OF, et al: Fetal endoscopic myelomeningocele closure preserves segmental neurological function. Dev Med Child Neurol 54:15-22, 2012

33. Wilson RD, Johnson MP, Crombleholme TM, Flake AW, Hedrick HL, King M, et al: Chorioamniotic membrane separation following open fetal surgery: pregnancy outcome. Fetal Diagn Ther 18:314-320, 2003

34. Wilson RD, Lemerand K, Johnson MP, Flake AW, Bebbington M, Hedrick HL, et al: Reproductive outcomes in subsequent pregnancies after a pregnancy complicated by open maternal-fetal surgery (1996-2007). Am J Obstet Gynecol 203:209.e1-209.e6, 2010
35. Winder FM, Vonzun L, Meuli M, Moehrlen U, Mazzone L, Krähenmann F, et al: Maternal complications following open fetal myelomeningocele repair at the Zurich Center for Fetal Diagnosis and Therapy. Fetal Diagn Ther 14:1-6, 2018

36. Zamłyński J, Olejek A, Koszutski T, Ziomek G, Horzelska E, Gajewska-Kucharek A, et al: Comparison of prenatal and postnatal treatments of spina bifida in Poland-a non-randomized, single-center study. J Matern Fetal Neonatal Med 27:1409-1417, 2014

\section{Disclosures}

The authors report no conflict of interest concerning the materials or methods used in this study or the findings specified in this paper.

\section{Author Contributions}

Conception and design: all authors. Acquisition of data: Licci. Analysis and interpretation of data: Licci, Soleman. Drafting the article: Licci. Critically revising the article: all authors. Statistical analysis: Licci, Soleman. Administrative/technical/material support: all authors. Study supervision: Guzman, Soleman.

\section{Correspondence}

Maria Licci: University Hospital of Basel, Switzerland. marialucia.licci@gmail.com. 